\title{
Criterion of aerodynamic performance of large-scale offshore horizontal axis wind turbines *
}

\author{
Zhao-xue CHENG (程兆雪 $)^{1}$, Ren-nian LI (李仁年) $)^{1}$, \\ Cong-xin YANG $(\text { 杨从新 })^{1}$, Wen-rui HU (胡文瑞 $)^{1,2}$ \\ (1. Lanzhou University of Technology, Lanzhou 730050, P. R. China; \\ 2. Institute of Mechanics, Chinese Academy of Sciences, Beijing 100080, P. R. China)
}

(Contributed by Wen-rui HU)

\begin{abstract}
With the background of offshore wind energy projects, this paper studies aerodynamic performance and geometric characteristics of large capacity wind turbine rotors ( 1 to $10 \mathrm{MW}$ ), and the main characteristic parameters such as the rated wind speed, blade tip speed, and rotor solidity. We show that the essential criterion of a highperformance wind turbine is a highest possible annual usable energy pattern factor and a smallest possible dimension, capturing the maximum wind energy and producing the maximum annual power. The influence of the above-mentioned three parameters on the pattern factor and rotor geometry of wind turbine operated in China's offshore meteorological environment is investigated. The variation patterns of aerodynamic and geometric parameters are obtained, analyzed, and compared with each other. The present method for aerodynamic analysis and its results can form a basis for evaluating aerodynamic performance of large-scale offshore wind turbine rotors.
\end{abstract}

Key words offshore wind energy project, horizontal axis wind turbine, rotor aerodynamic design, annual usable energy pattern factor, power coefficient, wind turbine rotor, wind turbine blade

Chinese Library Classification TK83

2000 Mathematics Subject Classification 76 N15

\section{Introduction}

Offshore wind energy technology is the frontier of wind energy development all over the world. West European countries began to install large-scale offshore wind generators in the $1990 \mathrm{~s}^{[1-3]}$ in order to explore the technical problems that were not encountered on land. Because of an abundance of wind resource, stability of wind speed and wind orientation, and less strict demand on environment protection, these countries constituted a series of large-scale development programs for offshore wind energy projects ${ }^{[1-2]}$ at the beginning of this century, and large-scale wind generators with an overall output of $150000 \mathrm{MW}$ will be installed offshore

* Received Sept. 10, 2009 / Revised Nov. 12, 2009

Project supported by the National Basic Research Program of China (973 Program) (No. 2007CB714605)

Corresponding author Ren-nian LI, Professor, E-mail: lirn@lut.cn 
before the year 2020. Although in the U. S. and Canada, in contrast to Europe, there is still a great potential for inland development of wind energy utilization ${ }^{[3]}$, the two countries are also going to set up offshore wind farms with a total output amounting to more than $1000 \mathrm{MW}$. In China, according to a policy of technology importation, assimilation, and autonomy-making, wind farms installed with wind turbines of 1.5-MW single-unit output were successfully set up on the mainland (in the deserts of Inner Mongolia, Xinjiang, Gansu, and Ningxia). Perhaps because there are still plenty of deserts in China for wind energy development, and the technique of manufacturing MW-level units and their mounting at inland wind farms has nearly been mastered, offshore wind energy projects have not yet been taken as an urgent task. Nevertheless, some farseeing people in China have taken the topic of offshore wind energy development into preliminary and serious consideration ${ }^{[1]}$. The offshore wind resource has been preliminarily investigated and analyzed, and the potential challenge in offshore wind energy projects has been discussed both technically and economically. It has been especially pointed out that development of offshore wind power projects should become an urgent task in China, and offshore wind farms should be built as soon as possible.

A detailed survey of wind resources in a favorable area on the sea is an urgent task for planning an offshore wind energy project. A comparatively accurate characterization of the annual frequency of the mean wind velocity and wind shear should be determined for the candidate offshore wind farm. Because of the large capacity of offshore wind turbines, the major technical problems are the gigantic construction, the sophisticated underwater groundwork, and the correlated mechanical analysis and investigation. Aerodynamic analysis and computation of the wind turbine rotor is, of course, one of the theoretical and technical topics of largescale offshore wind turbines. Based on the aerodynamic principle and operational method, the turbine rotor of an offshore unit is similar to that on land. Because of more stable wind velocity and orientation and lower wind turbulence on the sea, the evaluation of aerodynamic characteristics may be more accurate in the case of offshore wind turbine than the inland one. Certainly, the operational conditions on the sea such as gales, hurricanes, wind-wave coupling, and sever swaying of the mast (in the case of floating foundation) will bring about an unfavorable influence on the aerodynamic analysis of the characteristics of wind turbines. The smaller units rated with lower capacity and technically well-designed at present on land should be first installed offshore as trial units for collecting technical data that investigators need for offshore wind energy development.

A wind turbine with large capacity is most favorable on the sea, where it is unnecessary to pay excessive attention to some problems that are hard to overcome on land, such as occupation of farm land, noise contamination, shipment of gigantic components of wind turbine. It is generally taken for granted that the larger the capacity is, the bigger the size of the turbine rotor and its other components are. Is this absolutely so? The dimension of the turbine rotor and the related components are mainly decided by the air density at the wind farm, rated capacity of the machine, rated rotating speed, rated wind speed, and aerodynamic performance of the rotor. The last two parameters can be optimized with the effort of turbine researchers. The bigger dimension of the rotor is resulted mainly from unreasonable determination of the rated wind speed. Logically speaking, any wind speed within the operational range might be taken as a rated one if only a maximum annual electricity output can be obtained accordingly. Therefore, the wind speed with the highest annual distribution density or the annual mean wind speed, which is a little bit higher than the former, is generally taken as the rated one, expecting to get maximum annual electricity production. Generally, this rated speed is much less than the upper limit of the operational range. When the wind speed is higher than the rated one, the output of the rotor is limited to a constant as a rated one by means of blade pitch regulation so that the energy of higher wind is not absorbed completely and its larger portion is lost. Besides, when the wind speed is lower than the rated one and the blade pitch control is improper or not implemented at all (as related in paragraph 8.2.1 in [5]), the performance of the turbine 
rotor (power coefficient) will drop greatly so that a large portion of the wind energy is also not absorbed. Suppose that the rated wind speed is selected in such a manner that a higher wind speed with an annual distribution probability that is not so high as the maximum one is taken as the rated one and, at the same time, the blade pitch in the case of low wind is regulated so that the aerodynamic performance of the rotor can be kept as high as possible. Then a higher annual power generation might be achieved due to both the exploitation of high wind and the reasonable pitch regulation in the case of low wind. To do this, a parameter called the annual "usable energy pattern factor" [5] will be introduced in this paper to make a judgment on which wind speed would make this factor maximum, then would make the annual power yield maximal from the wind turbine designed with the rated wind speed so selected. It will be known from the following paragraphs that the above-mentioned usable energy pattern factor is closely related to the characteristics of annual wind speed frequency (distribution probability) at wind farms and the power coefficient of the rotor operated in whole wind conditions. In addition, the circumferential velocity of the blade tip and rotor solidity obviously have an influence on the power coefficient and, in consequence, on the usable energy pattern factor. For clarity, several large-capacity wind turbines (from 1 to $10 \mathrm{MW}$ ) are taken as the investigation focus to analyze the influence of three key aerodynamic and geometric parameters (the rated or design wind speed, the circumferential velocity of blade tip, and the rotor solidity) on the aerodynamic performance and geometric characteristics of the turbine rotor. We find a way to make the wind turbine generate a maximal annual power output with possible minimum dimension of the rotor. It is expected that the research in this paper would be useful for the investigation and development of offshore wind energy projects.

\section{Annual usable energy pattern factor}

Because of the large-capacity feature of offshore wind energy converters, a little improvement in their converting efficiency, on one hand, will result in a great increase of their power output. On the other hand, due to their gigantic dimension, various loads will also increase as a consequence ${ }^{[1-2]}$, so that the dimension and cost of their construction will correspondingly increase. Therefore, the improvement in their capability of wind energy absorption and the ratio of unit electricity generation capability to structural dimension will bring on a considerable economic benefit. At present, the horizontal axis wind turbine is the first option as an offshore wind energy converting device. From the above-mentioned two viewpoints, the aerodynamic characteristic parameters should be determined in terms of the following principle: make the annual usable energy pattern factor $\left(K_{\mathrm{u}}\right)$ and the power coefficient $\left(C_{\mathrm{P}}\right)$ of the rotor optimal, make its diameter $(D)$ as small as possible, increase its rotation speed $(n)$ as high as possible, and adopt a proper rotor solidity $(\sigma)$. Obviously, all of these are directly related to the design or rated wind speed $\left(V_{0}\right)$, the airfoils selected for the blade sections, the circumferential velocity of blade tip $\left(U_{0}\right)$, and the number of blades on the rotor $(z)$.

In order to analyze and evaluate the annual usable energy pattern factor, the necessary offshore meteorological data are selected as follows:

(1) Annual mean temperature $T_{\text {ave }}=15^{\circ} \mathrm{C}$, atmospheric pressure $p_{\mathrm{a}}=1.0 \mathrm{~atm}$, air density $\rho=1.225 \mathrm{~kg} / \mathrm{m}^{3}$, and kinematical viscosity of air $\nu=1.46 \times 10^{-5} \mathrm{~m}^{2} / \mathrm{s}$.

(2) Annual wind frequency characteristics: the Weibull wind speed probability distribution is adopted as China's offshore wind frequency characteristic, where the scale parameter is taken as $c=7.9$ (corresponding to the annual mean wind speed of $7 \mathrm{~m} / \mathrm{s}$ at the altitude of $10 \mathrm{~m}$ ) and the shape parameter is taken as $k=2.0$ as shown in Fig. 1.

(3) Wind shear characteristics: the exponential function with index of $\alpha=0.115$ is taken to specify the pattern of vertical variation of the wind speed as shown in Fig. 2. 


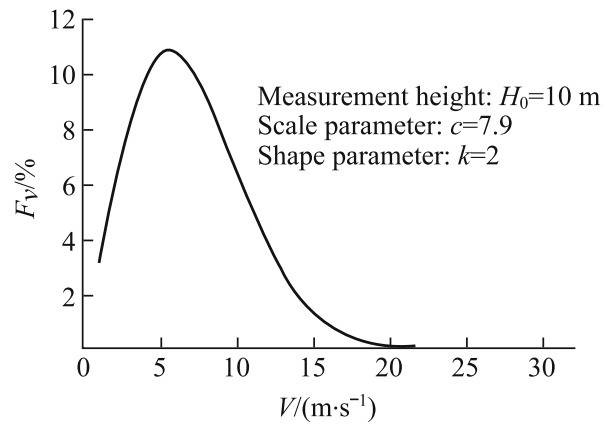

Fig. 1 Characteristics of annual wind probability density at China's offshore wind farm

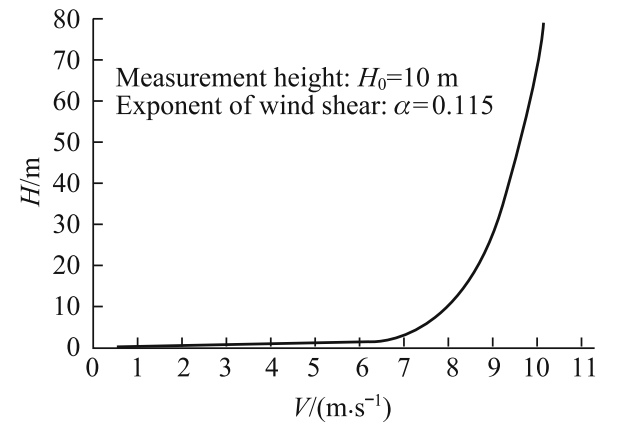

Fig. 2 Characteristics of wind shear at China's offshore wind farm

Annual usable energy pattern factor $K_{\mathrm{u}}$ is defined as ${ }^{[4]}$

$$
K_{\mathrm{u}}=\frac{C_{\mathrm{P} 0} V_{0}^{3}\left(T_{0}-T_{\mathrm{off}}\right)+\int_{T T_{0}}^{T_{\mathrm{st}}} C_{\mathrm{P}} V^{3} d t}{V_{\mathrm{ave}}^{3} T_{\mathrm{yr}}},
$$

where $C_{\mathrm{P} 0}$ is the power coefficient of the rotor operated in the rated condition, $V_{0}$ the rated wind speed, $T_{0}$ the number of hours in a year when the wind speed is higher than the rated wind speed, and $T_{\text {off }}$ the number of hours in a year when the wind speed is higher than the cut-off wind speed. Therefore, the former term in the numerator of the expression on the right side of Eq. (1) denotes the part of the wind energy absorbed by the rotor operated in a high wind condition. In the latter term of the numerator, $C_{\mathrm{P}}$ is the power coefficient of the rotor operated in wind with less speed than the rated one $\left(V<V_{0}\right), T_{\text {st }}$ is the number of hours in a year when the wind speed is greater than the cut-in wind speed. Thus, this integration term denotes the absorbed wind energy in the low wind condition. $V_{\text {ave }}$ in the denominator is the annual mean wind speed at the wind farm and $T_{\mathrm{yr}}$ the number of hours in a year (about 8760 $\mathrm{h} / \mathrm{a}$ ). This denominator will denote a reference factor of the wind energy available at the wind farm for a whole year. A turbine rotor with good aerodynamic performance should possess as high annual usable energy pattern factor $\left(K_{\mathrm{u}}\right)$ as possible during its whole operational range $\left(V_{\text {st }}<V<V_{\text {off }}\right)$.

In order to make a turbine operate with a higher power coefficient $\left(C_{\mathrm{P}}\right)$ in low wind $\left(V<V_{0}\right)$ and make the power output be limited to its rated level $\left(P_{0}\right)$ in high wind $\left(V>V_{0}\right)$, the rotor blade is to be pitch-controlled for the whole operational range. In the pitch control system with the output power as its feedback, the blade pitch is not regulated in low wind ${ }^{[5]}$, resulting in the excessive low power coefficient $\left(C_{\mathrm{P}}\right)$. In the pitch control system with the wind speed as its feedback, the blade pitch can be, however, regulated for the whole operational range so that not only the power output can be limited to the rated one in the high wind condition but the power coefficient can also be kept at a higher level in the low wind condition. It would be advantageous to make Eq. (1) have a discrete form as

$$
K_{\mathrm{u}}=\frac{C_{\mathrm{P} 0} V_{0}^{3}\left(T_{0}-T_{\mathrm{off}}\right)+\sum_{k=1}^{N} C_{\mathrm{P}, \max }(k) \times V(k)^{3} \times F_{v}(k) \times T_{\mathrm{yr}}}{V_{\mathrm{ave}}^{3} T_{\mathrm{yr}}},
$$

where $N$ is the number of the discrete wind speed during the operational range, and $F_{v}(k)$ the annual probability density of wind speed $V(k) . F_{v}(k)$ can be derived from the characteristics of annual frequency of the wind speed. As pointed out above, any wind speed within the 
operational range can be taken as the rated wind speed to design the turbine. However, only that which is selected after its optimization with $K_{\mathrm{u}}$ as objective function will be proper and favorable as the rated wind speed. Maximum annual electricity generation will be obtained with this wind speed as the rated one.

All temporal variables $(T)$ in Eq. (2) can be determined with the characteristics of annual frequency of the wind speed. Power coefficient $\left(C_{\mathrm{P} 0}, C_{\mathrm{P}, \max }\right)$, however, is to be given according to the adopted rated wind speed and pitch control mode as shown in Eq. (3) in the following paragraph. The process of the rated wind speed optimization and rotor aerodynamic optimization is, in fact, conducted and completed at the same time.

\section{Aerodynamic performance of rotor and its analysis}

The method of rotor aerodynamic optimization given in literature [8] is used to evaluate the parameters of turbine rotors with three blades and five rated capacities (from 1 to $10 \mathrm{MW}$ ). This method is set up on a linear vortex aerodynamic model with a finite number of blades and the induced velocity as well as the aerodynamic loads on the rotor blade are derived accordingly. Then the power and thrust coefficients of the rotor are given in the form as follows ${ }^{[8]}$ :

$$
\begin{aligned}
& C_{\mathrm{P}}=8 z \lambda_{0}^{3} \int_{r_{0}}^{1} \bar{\Gamma}\left[1 / \lambda_{0}-\bar{r}(\mu+\Delta \beta)\right] \bar{r} d \bar{r}, \\
& C_{\mathrm{F}}=8 z \lambda_{0}^{2} \int_{r_{0}}^{1} \bar{\Gamma}\left[\bar{r}+(\mu+\Delta \beta) / \lambda_{0}\right] d \bar{r},
\end{aligned}
$$

where the circulation $\Gamma$ and radii $r_{0}, r$ are expressed in their dimensionless form. Geometric and aerodynamic characteristic parameters will be optimized with both $C_{\mathrm{p}}$ and its correlative $K_{\mathrm{u}}$ as objective functions.

S-series airfoils with generally acknowledged good aerodynamic performance specified for wind turbine use are taken as the blade sections. In order to obtain a possibly higher annual usable energy pattern factor $\left(K_{\mathrm{u}}\right)$, the circumferential velocity of the blade tip $\left(U_{0}\right)$ is specially given a higher value of $100 \mathrm{~m} / \mathrm{s}$ (with the Mach number being about 3.0). A value of 85 or less is common for the wind turbine on land to avoid the unfavorable influence of air compression. Rotor solidity $(\sigma)$ is given a little bit higher value of 0.08 -level to get a higher power coefficient. Main aerodynamic and geometric characteristic parameters of the wind turbines with five different outputs and optimal annual usable energy pattern factor are shown in Table 1. In order to analyze the influence of the rated wind speed on $K_{\mathrm{u}}$, nine values of the

\begin{tabular}{|c|c|c|c|c|c|}
\hline Power, $P / \mathrm{kW}$ & 1000 & 2000 & 4000 & 7000 & 10000 \\
\hline Diameter, $D / \mathrm{m}$ & 28.8 & 40.76 & 57.6 & 76.1 & 91.1 \\
\hline Rated wind speed, $V /\left(\mathrm{m} \cdot \mathrm{s}^{-1}\right)$ & 19.2 & 19.16 & 19.2 & 19.2 & 19.2 \\
\hline Rotation speed, $n / \mathrm{rpm}$ & 66.25 & 46.85 & 33.13 & 25.11 & 20.95 \\
\hline Power coefficient, $C_{\mathrm{P}}$ & 0.3741 & 0.3741 & 0.3741 & 0.3761 & 0.3742 \\
\hline Annual usable energy pattern factor, $K_{\mathrm{u}}$ & 0.9649 & 1.0447 & 1.0922 & 1.1287 & 1.1562 \\
\hline Blade twist, $\Delta \Phi /\left(^{\circ}\right)$ & 32.92 & 32.92 & 32.92 & 32.92 & 32.92 \\
\hline Rotor solidity, $\sigma$ & 0.077 & 0.077 & 0.077 & 0.077 & 0.077 \\
\hline Blade volume, $v / \mathrm{m}^{3}$ & 11.7 & 33.1 & 93.5 & 214.8 & 369.5 \\
\hline Radial position of blade root, $R_{\mathrm{r}} / \mathrm{m}$ & 2.88 & 4.08 & 5.77 & 7.61 & 9.11 \\
\hline Chord of blade root, $B_{\mathrm{r}} / \mathrm{m}$ & 2.43 & 3.43 & 4.86 & 6.41 & 7.68 \\
\hline Setting angle of blade root, $\Phi_{\mathrm{r}} /\left(^{\circ}\right)$ & 30.33 & 30.33 & 30.33 & 30.33 & 30.33 \\
\hline Radial position of blade tip, $R_{\mathrm{t}} / \mathrm{m}$ & 14.41 & 20.38 & 28.83 & 38.03 & 45.57 \\
\hline Chord of blade tip, $B_{\mathrm{t}} / \mathrm{m}$ & 0.74 & 1.04 & 1.47 & 1.94 & 2.32 \\
\hline Setting angle of blade tip, $\Phi_{\mathrm{t}} /\left(^{\circ}\right)$ & -2.59 & -2.59 & -2.59 & -2.59 & -2.59 \\
\hline
\end{tabular}

Table 1 Main aerodynamic and geometric parameters of wind turbine rotors with five capacities 
rated speed are arbitrarily specified to evaluate the aerodynamic performance of a 2-MW rotor. The result is listed in Table 2 and depicted in Fig. 3. The influence of the circumferential velocity of the blade tip on $K_{\mathrm{u}}$ is evaluated for the 10-MW rotor with six arbitrarily given circumferential velocities of the blade tip, and the result is given in Table 3 and Fig. 4. Finally, the influence of the rotor solidity on $K_{\mathrm{u}}$ is also evaluated with six arbitrarily given values of the rotor solidity for 4-MW rotor, and the result is shown in Table 4 and Fig. 5.

First of all, the influence of capacity on annual usable energy pattern factor and power coefficient is analyzed. The five rotors with capacity from 1 to $10 \mathrm{MW}$ have the same circumferential velocity of the blade tip $\left(U_{0}\right)$ and the rotor solidity $(\sigma)$. It can be found from Table 1 and Fig. 3 that $K_{\mathrm{u}}$ increases with the capacity, the increment range amounts to $20 \%$ when the power increases from 1 to $10 \mathrm{MW}$. The power coefficient $\left(C_{\mathrm{p}}\right)$, however, stays almost unchanged. This is logically clear because these five rotors have almost the same rated wind speed and, therefore, have the same tip speed ratio and aerodynamic performance. Thus, it can be said that the more the capacity is, the stronger the ability of wind energy absorption

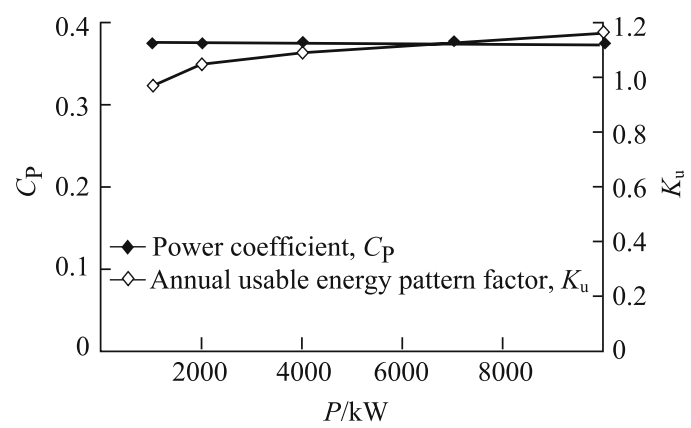

Fig. 3 Aerodynamic characteristics of wind turbine rotors with five capacities

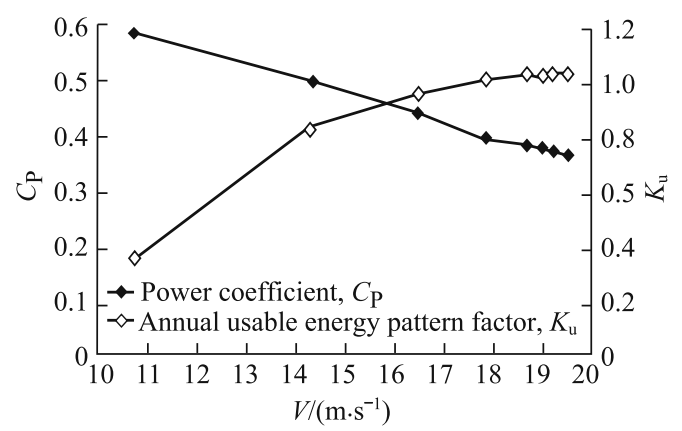

Fig. 4 Aerodynamic characteristics of 2-MW rotor

Table 2 Aerodynamic characteristics of 2 -MW rotor $\left(U_{0}=100 \mathrm{~m} / \mathrm{s}, \sigma=0.077\right)$

\begin{tabular}{lccccccccc}
\hline Rated wind speed, $V /\left(\mathrm{m} \cdot \mathrm{s}^{-1}\right)$ & 10.73 & 14.27 & 16.45 & 17.81 & 18.64 & 18.96 & 19.16 & 19.20 & 19.48 \\
\hline Power coefficient, $C_{\mathrm{P}}$ & 0.5920 & 0.5050 & 0.4434 & 0.3972 & 0.3865 & 0.3788 & 0.3741 & 0.3740 & 0.3667 \\
Annual usable energy & 0.3425 & 0.8349 & 0.9579 & 1.0081 & 1.0316 & 1.0150 & 1.0447 & 1.0349 & 1.0368 \\
$\quad$ pattern factor, $K_{\mathrm{u}}$ & 77.35 & 54.6 & 47.04 & 44.15 & 41.78 & 41.14 & 40.76 & 40.79 & 40.16 \\
Rotor diameter, $D / \mathrm{m}$ & 225.8 & 79.4 & 50.8 & 42 & 35.6 & 34 & 33.1 & 33 & 31.6 \\
Blade volume, $v / \mathrm{m}^{3}$ & & & &
\end{tabular}

Table 3 Aerodynamic and geometric parameters of 10-MW rotor $(\sigma=0.077)$

\begin{tabular}{lcccccc}
\hline Tip speed, $U_{0} /\left(\mathrm{m} \cdot \mathrm{s}^{-1}\right)$ & 60 & 70 & 80 & 90 & 100 & 120 \\
\hline Power coefficient, $C_{\mathrm{P}}$ & 0.187 & 0.222 & 0.281 & 0.32 & 0.374 & 0.469 \\
Annual usable energy pattern factor, $K_{\mathrm{u}}$ & 0.916 & 1.045 & 1.123 & 1.156 & 1.156 & 0.9714 \\
Rotor diameter, $D / \mathrm{m}$ & 128.8 & 113.8 & 105.2 & 98.5 & 91.1 & 84.82 \\
Blade volume, $v / \mathrm{m}^{3}$ & 1043.3 & 719.2 & 568.6 & 466.3 & 369.5 & 297.7 \\
\hline
\end{tabular}

Table 4 Aerodynamic and geometric parameters of 4-MW rotor $\left(U_{0}=100 \mathrm{~m} / \mathrm{s}\right)$

\begin{tabular}{lcccccc}
\hline Rotor solidity, $\sigma$ & 0.03 & 0.04 & 0.05 & 0.06 & 0.07 & 0.08 \\
\hline Power coefficient, $C_{\mathrm{P}}$ & 0.144 & 0.203 & 0.258 & 0.306 & 0.355 & 0.374 \\
Annual usable energy pattern factor, $K_{\mathrm{u}}$ & 0.63 & 0.737 & 0.891 & 0.985 & 1.061 & 1.092 \\
Rotor diameter, $D / \mathrm{m}$ & 99.3 & 78.3 & 69.4 & 63.7 & 61.7 & 57.6 \\
Blade volume, $v / \mathrm{m}^{3}$ & 102.8 & 73.9 & 72.3 & 75.9 & 89.9 & 93.5 \\
\hline
\end{tabular}




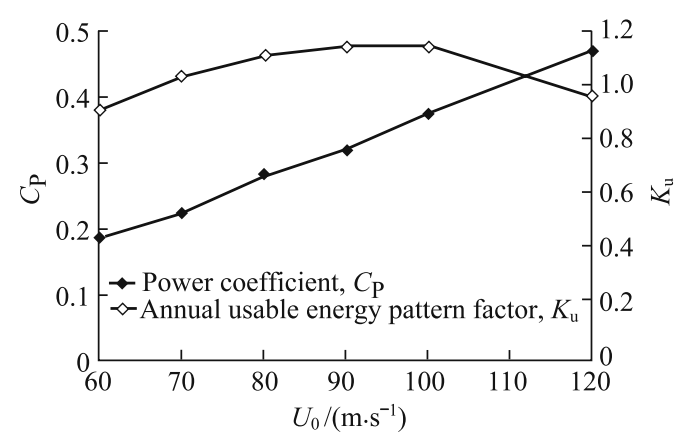

Fig. 5 Aerodynamic characteristics of 10MW rotor

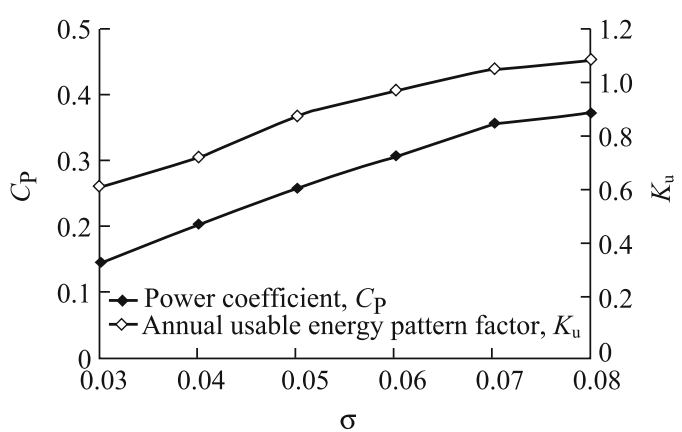

Fig. 6 Aerodynamic characteristics of 4-MW rotor

will be, and then the annual electricity generation will be relatively high.

Next, the influence of the three given parameters above (design or rated wind speed, circumferential velocity of blade tip, and rotor solidity) on the two main parameters of aerodynamic performance of the rotor is analyzed as follows.

(1) Influence of rated wind speed on rotor performance

It can be seen from Table 2 and Fig. 4 that reasonable selection of the rated wind speed is the most important factor that has a great influence on the aerodynamic and geometric characteristics. Naturally, it seems reasonable at first thought that the wind speed with the highest annual frequency or the one slightly higher than the annual mean wind speed has to be selected as the rated wind speed for rotor designing. However, this is not so. The data in Table 2 is for the $2-\mathrm{MW}$ rotor with nine different rated wind speeds from the lowest up to the highest, and all of them are higher than the annual mean wind speed. The data manifest that the annual usable energy pattern factor varies incrementally with the rated wind speed with the maximal increment range of $300 \%\left(K_{\mathrm{u}}=0.3425 \rightarrow 1.0447\right)$ although their power coefficients vary, on the contrary, decreasingly with a negative increment range of $37 \%\left(C_{\mathrm{P}}=\right.$ $0.592 \rightarrow 0.374$ ). Evidently, increasing the rated wind speed can make the capability of wind energy absorption of the rotor be greatly improved. This result comes from the reasonable blade pitch control in the low wind condition. Besides, both the rotor diameter and blade volume decrease greatly with the rated wind speed $\left(D=77.35 \rightarrow 40.76 \mathrm{~m}, v=225.8 \rightarrow 33.1 \mathrm{~m}^{3}\right)$, so that the dimension of the overall structure of the turbine can be greatly decreased, which is the most favorable effect.

(2) Influence of blade tip speed on rotor performance

The 10-MW rotor is taken here to discuss the influence of blade tip speed on rotor performance. Six circumferential velocities are assigned to the rotor tip $\left(U_{0}=60,70,80,90,100\right.$, $120 \mathrm{~m} / \mathrm{s}$ ). It can be seen in Table 3 and Fig. 5 that the annual usable energy pattern factor increases first and then decreases with $U_{0}$ and the power coefficient varies linearly and incrementally with $U_{0}$. The diameter of the rotor with higher blade tip speed is smaller by $29.3 \%$ than that with the lower blade tip speed $(D=91.1 \rightarrow 128.8 \mathrm{~m})$, and its capability of wind energy absorption is, on the contrary, greater by $20.8 \%$ than the latter $\left(K_{\mathrm{u}}=1.156 \rightarrow 0.916\right)$ and the power coefficient is doubled $\left(C_{\mathrm{P}}=0.374 \rightarrow 0.187\right)$.

(3) Influence of rotor solidity on rotor performance

The variation of rotor performance is discussed for the 4-MW rotor with six different solidities, which vary from 0.03 up to 0.08 -level. Circumferential velocity of blade tip is taken as $100 \mathrm{~m} / \mathrm{s}$. It is shown in Table 4 and Fig. 6 that both the annual usable energy pattern factor and power coefficient vary incrementally with rotor solidity $\left(K_{\mathrm{u}}=0.63 \rightarrow 1.092, C_{\mathrm{P}}=\right.$ $0.144 \rightarrow 0.374)$, and their increment range amounts to $73.3 \%$ and $160 \%$, respectively. The rotor diameter and blade volume, on the contrary, vary decreasingly with the rotor solidity. 
The increment range of the former amounts to $72.4 \%(D=99.3 \rightarrow 57.6 \mathrm{~m})$ and that of the latter is $9 \%\left(v=102.8 \rightarrow 93.5 \mathrm{~m}^{3}\right)$.

\section{Conclusions}

The following conclusions can be made after the foregoing discussion and analysis:

(1) Taking a wind speed greater than annual mean wind speed or a wind speed with a maximum annual frequency as the rated wind speed for wind turbine design is the key technical means for increasing the capability of annual electricity generation and decreasing the dimension of wind turbines although their power coefficient may not be maximal then. The premise of this conclusion is the reasonable pitch control in a low wind condition to make the power coefficient of the rotor as high as possible.

(2) Because of the features of the offshore environment, a higher tip speed ratio (a higher circumferential velocity of the blade tip) can be adopted for offshore wind turbines. Although the air compression may bring an unfavorable result of noise, not only the capability of annual electricity generation of the wind turbines will increase but also the dimension of the unit will decrease.

(3) Properly increase the rotor solidity is also a desirable technical means to increase the capability of annual electricity generation of wind turbines and decrease the dimension of the turbine rotor and the whole unit as well.

(4) In order to accurately determine the annual usable energy pattern factor of the wind turbine, two necessary premises should be guaranteed. First, the characteristics of annual wind speed frequency should be accurately determined by means of actually surveying the meteorological condition at the wind farm. Next, the blade pitch should be reasonably regulated in a low wind condition to guarantee a possibly higher power coefficient of the turbine rotor.

\section{References}

[1] Cheng, Changjun. Aerodynamic features and safety problems for wind turbine structures in offshore environment (in Chinese). Proceedings of National Workshop on Wind Turbine Aerodynamics, Gansu Science and Technology Press, Lanzhou, 12-19 (2007)

[2] Valpy, Bruce. UK Offshore Wind-Next Steps in Technology Development, Paper Collection, Global Wind Power, Beijing, 109-114 (2008)

[3] Camp, T. R., Johnston, M. J., Nichols, J., and Rainey, P. J. Advances in Modelling Techniques for Offshore Wind Turbines, Paper Collection, Global Wind Power, Beijing, 115-118 (2008)

[4] Le Gourieres, Desire. Wind Power Plants: Theory and Design, Pergamon Press (1982)

[5] Burton, Tony, Sharpe, David, Jenkins, Nick, and Bossanyi, Ervin. Wind Energy Handbook, Wiley \& Sons, Ltd, Chichester, 475-476 (2001)

[6] Cheng, Zhaoxue, Ye, Zhiquan, Chen, Jingyi, and Bai, Shibao. Aerodynamic optimization for the rotor of horizontal-axis wind turbine. Proceedings of International New and Renewable Energy Conference (ed. Zhu, Yajie), International Academic Publishers, Beijing, 306-312 (1990)

[7] Ye, Zhiquan, Cheng, Zhaoxue, Chen, Jingyi, and Bai, Shibao. Aerodynamic optimum design procedure and program for the rotor of a horizontal-axis wind turbine. Journal of Wind Engineering and Industrial Aerodynamics 39, 179-186 (1992)

[8] Cheng, Zhaoxue, Yang, Congxin, and Li, Rennian. A numerical method in aerodynamic computation for wind turbine rotor (in Chinese). Mechanics in Engineering 29(6), 44-47 (2007)

[9] Hillmer, B., Borstelmann, T., Schaffarczyk, P. A., and Dannenberg, L. Aerodynamic and structural design of multiMW wind turbine blades beyond $5 \mathrm{MW}$. Journal of Physics: Conference Series 75, 012002, 8pp (2007) DOI 10.1088/1742-6596/75/1/012002

[10] Knauer, Andreas and Hanson, Tor David. High tip speed operation for offshore wind turbines. Journal of Physics:Conference Series 75, 012002, 5pp (2007) 